\title{
Seminario «Las ciudades de América Latina entre el corto y el largo plazo»
}

Lima, 10-11 de diciembre de 2015

Jérémy Robert

\section{(2) OpenEdition}

Journals

Edición electrónica

URL: http://journals.openedition.org/bifea/7739

DOI: 10.4000/bifea.7739

ISSN: 2076-5827

\section{Editor}

Institut Français d'Études Andines

\section{Edición impresa}

Fecha de publicación: 1 diciembre 2015

Paginación: 509-510

ISSN: 0303-7495

\section{Referencia electrónica}

Jérémy Robert, « Seminario «Las ciudades de América Latina entre el corto y el largo plazo» », Bulletin de l'Institut français d'études andines [En línea], 44 (3) | 2015, Publicado el 08 diciembre 2015, consultado el 06 noviembre 2020. URL : http://journals.openedition.org/bifea/7739 ; DOI : https:// doi.org/10.4000/bifea.7739

Les contenus du Bulletin de l'Institut français d'études andines sont mis à disposition selon les termes de la licence Creative Commons Attribution - Pas d'Utilisation Commerciale - Pas de Modification 4.0 International. 


\section{SEMINARIO «LAS CIUDADES DE AMÉRICA LATINA ENTRE EL CORTO Y EL LARGO PLAZO»}

Lima, 10-11 de diciembre de 2015

El seminario «Las ciudades de América Latina entre el corto y el largo plazo» surgió del interés conjunto del Centro de Investigación de Arquitectura y Ciudad de la Pontificia Universidad Católica del Perú (CIAC-PUCP), del Departamento Académico de Ciencias Sociales y la Escuela de Gobierno y Políticas Públicas de la PUCP y del Instituto Francés de Estudios Andinos (IFEA-U mifre 17 MAEDI/CNRS USR 3337-América Latina). A este grupo se sumó también l'École Urbaine de SciencesPo Paris. Tiene como antecedente inmediato el seminario internacional «Derecho a la Ciudad: Lo Político de las Políticas U rbanas» realizado en Lima en agosto de 2014, organizado por el Grupo de Trabajo Derecho a la Ciudad del Consejo Latinoamericano de Ciencias Sociales (CLACSO ) conjuntamente con la PUCP, el IFEA y otras institucionales nacionales e internacionales.

La propuesta central del seminario ha sido de discutir, desde la Academia, la articulación de las acciones de corto

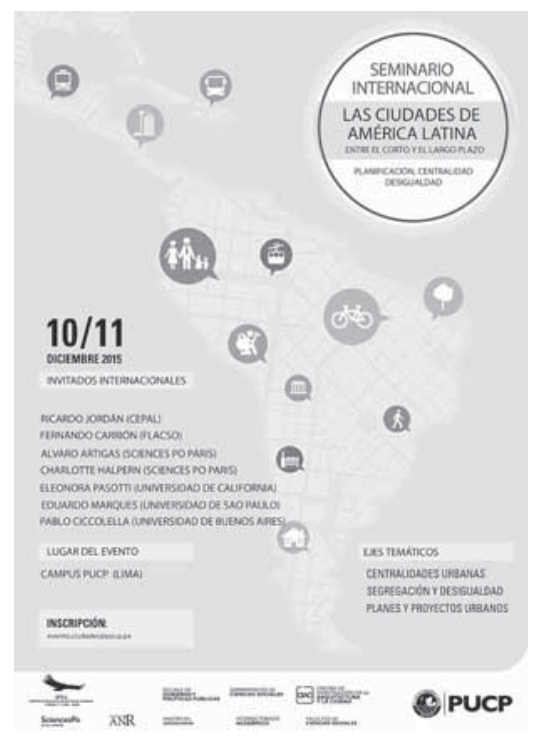
plazo con los desafíos a largo plazo en las ciudades latinoamericanas. Esta reflexión parte de la tensión conocida por los gobiernos locales para producir resultados legítimos ante el electorado, frente a la necesidad de planificar el futuro de su ciudad. Además de esta dualidad temporal, surgen nuevos desafíos en torno a la naturaleza de los problemas a resolver: siguen los problemas de fondo (inclusión social, pobreza, servicios básicos), aparecen nuevas demandas (diversificación de las reivindicaciones y de las esperanzas como medio ambiente, cultura, etc.). Se plantearon algunas de las preguntas que guiaron las reflexiones: ¿Cómo se han gobernado las ciudades de América Latina? ¿En qué medida la estructura institucional del gobierno de la ciudad incide en las políticas urbanas? ¿Cuál ha sido el rol de la planificación urbana? ¿Q ué retos presenta el crecimiento de las ciudades y los cambios en su estructura para la gestión urbana? ¿Q ué respuestas ha dado la gestión urbana a la desigualdad social y urbana?

Con esta propuesta, el seminario ofreció dos días de conferencias y debates muy densos. 0 cho invitados internacionales, acompañados de tres invitados nacionales animaron cinco mesas centrales. Fernando Carrión (FLACSO Ecuador) introdujo el seminario junto con Pablo Ciccollela (U niversidad de Buenos Aires) en una primera mesa «Centros y centralidades en América Latina», ofreciendo unas reflexiones sobre la naturaleza de los centros y su relación con la historia urbana y sobre el mestizar en las ciudades. La mesa «Dinámicas de segregación urbana en América Latina» cerró el primer día con Eduardo Marques (Universidad de Sao Paulo) con el caso de Sao Paulo y Javier Herrera sobre las dinámicas limeñas (PUCP). A partir 
de las estadísticas, los dos ponentes evidenciaron cómo grandes transformaciones sociales toman pie y evolucionan en las ciudades. El segundo día inició con las conferencias de Eleonora Pasotti (Universidad de California) y de Charlotte Halpern (Sciences Po Paris) en una mesa sobre «Políticas y gobernanza urbana». Tomando el caso de las movilizaciones en las ciudades que «aspiran a ser globales» 0 de los grandes aeropuertos, las conferencistas propusieron un análisis de los conflictos que animan las ciudades y cómo revelan los entrecruces de su gobierno. Alvaro Artigas (Sciences Po Paris) a partir del caso del proyecto del Tren eléctrico de Lima, y Julio Calderón (UNI) con un análisis comparado de las políticas de vivienda en Perú, Colombia y Corea, ofrecieron sus aportes en la cuarta mesa central «La planificación urbana entre proyectos y políticas». El seminario culminó con brillo en una última conferencia de Ricardo Jordán (CEPAL) con el tema de «Las ciudades de América Latina hacia Hábitat IIl» comentada por Gustavo Riofrío.

A estas mesas centrales, se sumaron 11 mesas simultáneas con un total de 42 ponencias. Los temas de las mesas reflejan solo parcialmente la riqueza de los intercambios. Un primer grupo de mesa abordó el tema de las centralidades. U na primera entrada cuestionó las restructuraciones urbanas con aportes a varias escalas, desde centralidades intraurbanas hasta redes de ciudades regionales, completada por unas propuestas desde la problemática del transporte.

El tema de la segregación constituyó un eje fuerte del seminario y de cuatro mesas simultáneas en particular. Varias entradas fueron trabajadas, impulsando una reflexión más bien general sobre las dinámicas de segregación, de integración y los patrones de conveniencia urbana o más específica sobre el hábitat popular y las producción del espacio urbano. Trabajos sobre las expresiones o materialización de las desigualdades en el espacio público, así como las representaciones urbanas (contemporáneas o históricas) completaron este bloque.

El tema de la planificación juntó también a numerosas propuestas, con aportes diversos y originales. Las reflexiones sobre las tendencias y problemáticas de la planificación urbanas fueron complementadas por aportes sobre los desafíos de la gestión urbana: fueron tocadas tanto la cuestión de los instrumentos del gobierno de la ciudad como de la gobernanza. Dos mesas plantearon entradas más específicas, por un lado con las políticas habitacionales y los mercados de suelo, y por otro lado con reflexiones sobre la relación entre la planificación urbana, la vulnerabilidad y los riesgos.

Con estostemas, el seminario ofreció unas miradas diversas y complementarias sobre las ciudades latinoamericanas, y muchas perspectivas. La riqueza de las reflexiones se debió en parte a la gran diversidad de países latinoamericanos representados con ponentes de Chile, Argentina, Brasil, Colombia, Ecuador, Bolivia y Venezuela, también acompañados por Estados U nidos y Francia (que sumó 8 ponentes), pero también de disciplinas y de formas de abordar los procesos urbanos. A tanto éxito, un cierto pesar: la poca presencia de académicos desde las ciudades de provincia de Perú, donde el tema urbano plantea tantas preguntas y nuevos desafíos. 